\title{
Italian train derailment and the civil protection emergency psychologist intervention: A case report.
}

\author{
Riccardo Biella, ${ }^{1}$ Liliana Artale ${ }^{2}$ \\ ${ }^{1}$ Psychosocial Emergency Team (SPE), Spazio Vita Niguarda, European Institute of Psychotraumatolgy and \\ Stress Management (IEP); ${ }^{2}$ Psychosocial Emergency Team (SPE), Psychologist Psychotherapist, \\ Psychotraumatologist
}

\begin{abstract}
In the last years the mind-body unity, and so giving both physical and psychological attention, is entering increasingly in the first-responder system. This paper reports the intervention done by the Psychosocial Emergency Team, the Civil Protection Emergency Psychologists, during the multi-forces' intervention on the Limito di Pioltello train crash, a major accident occurred in Italy in 2018. The attempt is to give a photography of the psychological part of the rescue system in this scenario, showing phases,
\end{abstract}

\footnotetext{
Correspondence: Riccardo Biella, Società Cooperativa Sociale Spazio Vita, Piazza Ospedale Maggiore 3, 20162 Milano, (MI), c/o Unità Spinale A.S.S.T Grande Ospedale Metropolitano Niguarda.

Tel.: +39.02.66114333;

Fax: +39.02.6472490;

E-mail: biella.riccardo@gmail.com.
}

Key words: Emergency psychology; maxi-emergency; rescue system; psychological technical procedures; psychological support.

Contributions: Both the authors authored and edited the manuscript, and they were active operators during the Limito di Pioltello train crash.

Conflict of interest: No one. This work was not supported by any grant.

Acknowledgments: We'd like to thank all the SPE team and especially all the colleagues that were active that day: Sbattella F, Puglielli M, Battiato G, Garzia G and Cannizzo N, our precious second line. We also would like to thank Milan Metropolitan City to believe in our service contribution and the great team of the Milan Civil Protection, all the operators and the Coordination Committees for Volunteering (CCV).

Conference presentation: The content in the following article resume the presentation held by the authors during the convention 'Defending physical and mental health in maxi-emergencies', hosted by the University of Sacred Heart - Milan, in October 3, 2019.

Ethics approval and consent to participate: The manuscript does not contain any elements that would allow the recognition of the patient

Received for publication: 16 November 2019.

Accepted for publication: 13 February 2020.

This work is licensed under a Creative Commons Attribution 4.0 License (by-nc 4.0).

Copyright: the Author(s), 2020

Licensee PAGEPress, Italy

Emergency Care Journal 2020; 16:8683

doi:10.4081/ecj.2020.8683 methods, and some rationales subtended in our actions. The aim is to share procedures and open a constructive dialogue that could bring to more standardized interventions among non-governmental emergency psychologist teams with the aim to always provide better care both to victims and their families.

\section{Introduction}

A maxi-emergency, as a complex incident, is a sudden, unexpected event that involves a large number of people in a limited period of time, in a limited area and that exceeds normal forces to respond, ${ }^{1}$ causing a risk of derangement in people's sense of continuity and security, dangerous for mental well-being. ${ }^{2}$ This kind of event, indeed, creates a temporary, but not so short, imbalance among rescue and support needs and available resources. ${ }^{3}$ This imbalance psychologically puts great stress on people's capacity to react and adapt, and individuals' and communities' ordinary coping abilities, let by themselves, could not be enough. ${ }^{4}$ Extreme sensory stimuli and emotions, could also overwhelm normal functioning, and reactions could fall into aggressive or inappropriate behavior, ${ }^{5}$ harmful in such a complex emergency situation.

Emergency psychologists are the field operators that help people to deal with all this powerful experience. ${ }^{3}$ A new important ally to rescuers teams, arose in Italy at the turn of this century to cope with disasters, and today also active during complex accidents.

\section{Case Report}

North Italy, January 25th, 2018, 6.57 am, the 10452 Trenord train, from Cremona to Milan is travelling with 350 commuters on board. In Milan outskirts, just passed Pioltello-Limito station, while travelling at $140 \mathrm{~km} / \mathrm{h}$, one of the three wagons derails hitting the power lines poles, and causing the death of 3 people and 46 injured, 5 of them in life-threatening conditions. Immediately first responders are activated, fire fighters to cut plates, rescuers with helicopters and ambulances for injured, police to close the zone, Civil Protection to complete the red zone setting, and Civil Protection Emergency Psychologists (SPE - Emergency Psychosocial Team) for victims' families.

Pre-alert about a possible intervention reached the SPE at 8:10 a.m. As specialized though volunteers psychologists we need to start to plan how to get free of every commitment and to possibly compose the team. Alert and request to intervene arrived from Milan Metropolitan City at 8:30 a.m. One of the team started to contact the rescue coordinator on field and the other authorities by telephone, becoming our Second Line (SL), our connection with the high frame of the rescue operations. By our service agreement 
we guarantee to be ready on field within 2 hours. In this time a first operator reached the crash zone and took contact with the rescue forces coordinator, becoming the psychological aid coordinator and started the first psychological support to victims' family members, already aware of the death of their beloved. A mother was in contact with the daughter during the accident. Afterwards, at 11:15 a.m., the rest of the team, 4 operators, arrived with the van bringing all the selected materials and immediately started giving support to the families. Possibility to assist also injured passengers evacuated in a near school gym was evaluated, but transfer to hospitals was almost done and we decided not to dissipate forces in a limited effectiveness intervention (Strategic Resources Management). When victims' bodies were prepared for recognition, at 11:45 a.m. with our and other forces vans, families were transported at the morgue, never stopping the psychological support meanwhile. SPE coordinator and another operator stayed on the red zone for ongoing and possible requirements and reached the morgue in stages, one at 12:30 a.m. and the second one at 13:30, in correspondence with decreasing possibility of other requests, also by media. At the morgue family members were assisted before, during and after the vision of the relative death body. SPE managed the space to guarantee privacy to each one and a proper space for sorrow, mediating also contacts with political presence for condolences. When primal necessity has been satisfied, families and relatives emotionally reconnected and stabilized and psychoeducation about possible forthcoming reactions administered, we considered our intervention concluded. At 14:30 we took leave from them, leaving our contacts, giving availability for eventual future needs to be connected with psychological services on their area and saluting each of them. We talked with some operators from other forces, reviewing the operations. At 15:00 we had lunch and decompressed our emotional fatigue also with a first technical debriefing.

\section{Discussion}

In every mass-casualty our actions are guided by eight targets: ${ }^{3}$ i) first contact and approach; ii) assurance and protection; iii) emotional stabilization; iv) people assessment; v) assistance for primary problems; vi) family reconnection; vii) psychoeducation about stress and coping; viii) linking to territory services. As we have seen, this is not a rigid sequence of behaviors but overlapped goals, mainly to pursuit in a parallel way, and that need to be done for every victim on the emergency scene. For such an action, we also need an organizational framework and peculiar tools.

First of all, is our Civil Protection (CP) uniform with the 'psychologist' patch clearly visible. This make us recognizable and acknowledged, people by culture know who we are, what are we there for, plus all this added to and declined in our specific function. In many cases our primary way to approach is mediated by a physical way of caring, and for this reason we always have primary support material for basic needs. Our main goal in the intervention first phase is to restore physical security, naturally bringing patients outside the red zone but also with water, food, blankets, protection from sun or rain, etc. to communicate to their body that they are safe. ${ }^{2,5}$ Relatively to create the feeling of safeness, one of the most important non-physical tool is what we call Fluid Setting Management (FSM), Environmental and Relational. Environmental FSM requires to think about the ongoing rescue procedures, and to set the victim/family gathering point most possible away from stress stimulations (visual and auditory), in that time and considering its evolution over the rescue and securing process, anticipating strategically possible other operators' field and paths needs. When we talk to people, we also position ourselves in a way that their visual (and possibly auditory) field is the most possible free from stressful scene or movement.

Relational FSM, in the same way, requires creating a safe and protected social environment. We reconnect victims with their families and, on an emotional level, among family members. We become referent about communications from rescue operators and we mediate or explain/reinterpret every difficult communication that's needed to be given directly from them. We also limit or block every intrusive or disturbing contact from other people (ex. crowd, media). We hold institutional representative contact to the family until the right moment and, of course, we protect the privacy and intimacy of our discussions with people. Trying to reach these goals team work is fundamental, like in a basketball field we know where other colleagues are and what are they doing, and at the same way as passing the ball, we take action differently in specific interventions, or as the block move while dribbling, talking gently or creating, in an easy way, a barrier with our bodies we hold or stop other people to go across our setting, getting near colleagues talking with people and/or near people in need of a quiet space.

We try to do all of this in a way that communicates a feeling of control and calm, trying to be ourselves a source of safeness so.

When the psychophysics activation allows it, and/or in function to give to a person reaction a meaning useful to decrease it, we give psychoeducation. They are usual reactions to unusual events, and they need to know it. In conclusion of our intervention we also explain possible reactions in the next days, how to deal with them, give information that spaces from nutritional and sleep hygiene, to stress management techniques, and who to call if all this persist. We give them the team visit card explaining that we're available to look for them services in their residential area.

We're there to create a safety frame (physical, relational and emotional), to support them psychologically in order to promote a better events processing and bereavement, to help them to control possible dysfunctional behavior and assessing people at risk to develop stress related disease, and in this we take our efficacy indicators, but we're always aware that other needs and manifestations could arise in the next days.

At the end of our services we use a warm closure, every team member leaves the field greeting the families in a warm and respectful way. We entered in their lives and established a relation, by person or by uniform presence, and we cannot disappear, ripping off this bond.

Once finished with families we address our attention to present operators, for an informal decompression and, in case of need, when not already predisposed by their corps or institution, offering our availability for defusing or (emotional) debriefing. ${ }^{6}$ Because even operators could be affected by the extreme events they managed. With whom we interacted, or were present next to us, we also give a warm closure, and by telephone to the coordinators.

Once left the field we give attention to ourselves, and we take our time for decompression and to evaluate the necessity for an emotional debriefing. In the next days, also considering our second line, we give support to whom experimented difficulties and an emotional debriefing if needed. A full technical debriefing, a technical analysis of the intervention, is done at the monthly meeting.

\section{Conclusions}

The Limito di Pioltello train crash required a multi-forces 
intervention in which also $\mathrm{CP}$ emergency psychologist team intervened. Preparation, by specific knowledge and constant training, permitted a planned, coordinated and integrated performance resulting in an effective sustain to victim's families, from the crash field to the morgue, without forgetting of operators too.

But we could do more. Sharing methodologies, standardizing rationales among Emergency Psychology Associations interventions, we could be better identified by the entire rescue system, and through adequate and verified training requirement guarantee a standardized level of effectiveness. In this way, regardless of the organization and its geographical distribution, we could be perceived by the rescue system as predictable and reliable, increasing our integration with the rescue system and so the interventions effectiveness.

The mind-body unity paradigm is now accepted and is evident during emergency situations: also people expectations for emotional care.

Emergency Psychology should be an expected and essential part in the rescue system but as emergency psychologists we first have to make steps in this direction.

\section{References}

1. Italian regulation. Law regarding establishment Civil Protection National Service. LD 225/1992 in: Gazzetta Ufficiale No. 54 24/2/1992, pp 3-13.

2. Van der Kolk BA. The body keeps the score: brain, mind, and body in the healing of trauma. Penguin Group, 2015.

3. Sbattella F. Manuale di psicologia dell'emergenza. Franco Angeli, 2009.

4. Kleber RJ, Figley CR, Gersons BPR. Beyond trauma: cultural and societal dynamics. Springer, 2013.

5. Porges SW. The polyvagal theory: neurophysiological foundations of emotions, attachment, communication, and self-regulation. WW Norton \& Co, 2011.

6. Everly GS, Mitchell JT. Critical Incident Stress Management (CISM): a new era and standard of care in crisis intervention. Chevron Pub Corp, 1999. 